\title{
Synthesis of agar-stabilized nanoscale zero-valent iron particles and removal study of hexavalent chromium
}

\author{
C. Jiao $\cdot$ Y. Cheng $\cdot$ W. Fan $\cdot$ J. Li
}

Received: 24 May 2013/Revised: 9 January 2014/ Accepted: 3 February 2014/Published online: 27 February 2014

(C) Islamic Azad University (IAU) 2014

\begin{abstract}
In this study, agar-stabilized nanoscale zerovalent iron (A-nZVI) was synthesized using a rheological phase reaction method. The structure and morphology of A-nZVI particles were investigated by X-ray powder diffraction, scanning electron microscopy, transmission electron microscopy and Fourier-transform infrared spectrometry. Batch removal experiments showed that the $\mathrm{pH}$ value of solution, hexavalent chromium [Cr(VI)]/A-nZVI mass ratio and reaction time have significant effects on the removal of $\mathrm{Cr}(\mathrm{VI})$. A $100 \%$ removal of $\mathrm{Cr}(\mathrm{VI})$ was achieved when applying $50 \mathrm{mg} \mathrm{L}^{-1}$ of $\mathrm{Cr}(\mathrm{VI})$ at the optimal $\mathrm{pH}$ value of 3 and the $\mathrm{Cr}(\mathrm{VI}) / \mathrm{A}-\mathrm{nZVI}$ molar ratio of 0.025 with the reaction time of $2 \mathrm{~h}$ at room temperature. The removal rates of $\mathrm{Cr}(\mathrm{VI})$ were fitted to the modified pseudo-first-order kinetic equations with respect to $\mathrm{Cr}(\mathrm{VI})$ concentrations.
\end{abstract}

Keywords Agar-stabilized nanoscale zero-valent iron · Rheological phase reaction - Hexavalent chromium . Removal efficiency

C. Jiao · Y. Cheng $(\bowtie) \cdot$ W. Fan

School of Materials Science and Engineering, Jingdezhen Ceramic Institute, Jingdezhen 333403, Jiangxi Province, China e-mail: cy_jci@yahoo.com.cn

C. Jiao $\cdot$ Y. Cheng $\cdot$ W. Fan

Key Laboratory of Jiangxi Province for Advanced Ceramic Materials, Jingdezhen 333001, Jiangxi Province, China

J. Li

School of Environmental and Biological Engineering, Nanjing University of Science and Technology, Nanjing 210094, Jiangsu Province, China

\section{Introduction}

Hexavalent chromium is a heavy metal used in a variety of industrial applications which is highly toxic to humans, animals, plants and microorganisms (Gheju 2011). Chromium contamination of aqueous solution has received increasing attention because of its severe impact on public health. Common hexavalent chromium [Cr(VI)] exposure has several contact pathways such as ingestion, inhalation and derma. $\mathrm{Cr}(\mathrm{VI})$ has significant effect on human health such as gastrointestinal, respiratory and immunological systems, which can also cause reproductive and development problems. Therefore, it should be removed from contaminated waters. Its reduction to trivalent chromium can be beneficial because a more mobile and more toxic chromium species is converted to a less mobile and less toxic form. Several treatment technologies have been reported for the removal of $\mathrm{Cr}(\mathrm{VI})$, including phytoremediation, microbial remediation, chemical reduction, physical sorption (using ion exchange resin, activated carbon etc.) and membrane filtration (ultra filtration, nanofiltration and reverse osmosis) (Owlad et al. 2009). The use of nanoscale zero-valent iron (nZVI) has gained an increasing interest in remediation of surface water, groundwater and soil contaminated with a wide array of organic (Elliott et al. 2009; O'Carroll et al. 2013) and inorganic heavy metals contaminants (Flury et al. 2009; Franco et al. 2009).

The direct mechanism of $\mathrm{Cr}(\mathrm{VI})$ reduction is based on the capacity of nZVI to serve as electron donor. Additionally, ferrous iron released during $\mathrm{Cr}(\mathrm{VI})$ reduction by nZVI, as well as molecular hydrogen, atomic active hydrogen and solid minerals containing Fe(II) generated as products of nZVI corrosion, may also contribute to the reduction process. The rate of $\mathrm{Cr}(\mathrm{VI})$ reduction vary 
significantly depending on experimental conditions such as nZVI type, dose and pretreatment, $\mathrm{pH}$, water composition, temperature and $\mathrm{Cr}(\mathrm{VI})$ concentration.

The high remediation efficiency of nZVI is mainly attributed to its high surface area, high levels of surface defects, high density and decent intrinsic reactivity of surface sites, which make the nanoparticles very reactive in the degradation of contaminants (Singh et al. 2011). Nevertheless, nZVI particles synthesized from traditional methods tend to agglomerate rapidly in water via Van der Waals and magnetic attraction forces, forming particles with diameters ranging from several microns to several millimeters (He and Zhao 2005; He et al. 2007; Alidokht et al. 2011). In addition, conventional nZVI particles can react with the surrounding media (e.g., dissolved oxygen, water and other oxidizing agents), leading to the rapid loss of reactivity (He and Zhao 2005; Choi et al. 2009; Alidokht et al. 2011).

To stabilize the synthesized iron nanoparticles, several methods have been investigated. Anionic hydrophilic carbon (Schrick et al. 2004) and chitosan/silica (Zhu et al. 2006) were successfully employed as supports to inhibit the aggregation of iron nanoparticles. Starch (Alidokht et al. 2011) and carboxymethyl cellulose (He et al. 2007) were used as stabilizers to increase the particle dispersion and to improve reaction performance. Iron nanoparticles were immobilized onto supported polyelectrolyte multilayers to yield evenly distributed nanoparticles of uniform size (1-4 nm) (Huang et al. 2008).

Many methods have been used for the preparation of nZVI, such as chemical vapor deposition, inert gas condensation, pulsed laser ablation, spark discharge generation, sputtering gas-aggregation, thermal decomposition, thermal reduction of oxide compounds, hydrogenation of metallic complexes and aqueous reduction of iron salts (Crane and Scott 2012). The properties of metallic nanoparticles are affected by the composition and microstructure, which are sensitive to the preparation method used in their synthesis process.

The rheological phase reaction is the method for preparing compounds or materials from a solid-liquid rheological mixture. There are many advantages in the rheological phase system, such as efficient utilization of the surface area of solid particles, close and uniform contact between solid particles and fluid, good heat exchange and simple reaction temperature control. It is a novel, simple, and economical and efficient soft chemistry method (Jiang et al. 2007).

Agar is also a low-cost and environmentally friendly macromolecular skeleton compound that has been successfully applied as an effective stabilizer in the preparation of metal nanoparticles such as Ag (Shukla et al. 2012). Agar has good rheological properties (Norziah et al. 2006) that can efficiently utilize the surface area of solid particles. Agar can interact with iron nanoparticles, making them much more stable (He et al. 2007). This is mainly because iron nanoparticles surface is covered by electrically charged agar layers forming electrostatic repulsion and steric effect between molecules, making nano-scale iron particles separate from each other; hence, the dispersion of nanoscale iron was improved (Legrand et al. 2004).

In this study, agar-stabilized nZVI (A-nZVI) was synthesized by rheological phase reaction method and the performance for the removal of $\mathrm{Cr}(\mathrm{VI})$ from aqueous solution was investigated.

Materials and methods

\section{Preparation of A-nZVI}

The stabilized A-nZVI was synthesized as follows: FeS$\mathrm{O}_{4} \cdot 7 \mathrm{H}_{2} \mathrm{O}$ and $\mathrm{KBH}_{4}$ were mixed at the molar ratio of $1: 3$ by grinding in an agate mortar, and then, the solid mixture was added to an agar solution to form a rheological body. The mixture was then transferred into a three-necked round-bottom flask. The reaction was conducted under continuous stirring at room temperature. The solid product was collected by filtration, sequentially washed with deionized water and ethanol and dried under vacuum. All reaction processes were protected with nitrogen.

\section{Characterization of A-nZVI}

The X-ray powder diffraction (XRD) patterns were recorded using a Bruker D8 advance diffract meter (Bruker, Germany) with $\mathrm{Cu} \mathrm{K} \alpha$ radiation from $5^{\circ}$ to $70^{\circ}$ at a rate of $0.2^{\circ} \mathrm{s}$. The tube current was $100 \mathrm{~mA}$ and the tube voltage is $40 \mathrm{kV}$. The structure and morphology of A-nZVI particles were investigated by scanning electron microscopy (SEM) on a high-resolution SEM (JEOL-JMS-6700F, Japan) with an acceleration voltage of $10-30 \mathrm{kV}$. The micromorphology was characterized by transmission electron microscopy (TEM) on a high-resolution TEM (HRTEM, JEOL JEM-2010, Japan) with an acceleration voltage of $200 \mathrm{kV}$. Fourier-transform infrared (FT-IR) spectrometry recorded with a Nicolet 5700 (Nicolet, US). The spectra were collected with a resolution of $4 \mathrm{~cm}^{-1}$ in the range of $4,000-400 \mathrm{~cm}^{-1}$.

\section{Batch removal of $\mathrm{Cr}(\mathrm{VI})$}

The removal of $\mathrm{Cr}(\mathrm{VI})$ was carried out in batch mode at room temperature and atmospheric pressure. 250-mL conical flasks containing a certain amount of A-nZVI and $100 \mathrm{~mL}$ of $\mathrm{Cr}(\mathrm{VI})$ solution on a temperature-controlled shaker were stirred at $150 \mathrm{rpm}$. After a desired time, the 
solution was filtered through a $0.22-\mu \mathrm{m}$ cellulose membrane filter to separate out the solid particles.

The $\mathrm{Cr}(\mathrm{VI})$ concentration of filtrate was measured using 1,5-diphenylcarbazide method. First, $0.5 \mathrm{~mL} \quad \mathrm{H}_{2} \mathrm{SO}_{4}$ $(10+1)$ and $0.1 \mathrm{~mL} 1,5$-diphenylcarbazide were added to $5 \mathrm{~mL}$ water sample, respectively. Then, $\mathrm{Cr}(\mathrm{VI})$ was measured by using a $722 \mathrm{UV}$-Vis spectrophotometer at $540 \mathrm{~nm}$. The removal efficiency of $\mathrm{Cr}(\mathrm{VI})$ was calculated by Eq. (1),

$E_{\text {removal }}=\frac{\left(C_{0}-C_{t}\right)}{C_{0}} \times 100 \%$

where $C_{0}$ and $C_{t}$ are the concentrations of $\mathrm{Cr}(\mathrm{VI})$ solution at time $t=0$ and $t=t$, respectively.

\section{Results and discussion}

\section{XRD analysis}

In Fig. 1a, the XRD patterns of A-nZVI after 2 weeks of air exposure indicate the presence of body-centered cubic $\alpha$-Fe (110 and 220) $\left(2 \theta=44.83^{\circ}\right.$ and $65.22^{\circ}$, respectively). In addition, no signal of iron oxides $\left(2 \theta=35.46^{\circ}, 43.12^{\circ}\right.$, $53.50^{\circ}, 56.98^{\circ}$, and $62.64^{\circ}$ ) is observed, which indicates A-nZVI has good antioxidant activity. Additional XRD analyses indicate the poor crystalline structure of the nanocluster. Insufficient growth time leads to a tiny nanocluster and poor crystalline structure. After reacting with $20 \mathrm{mg} \mathrm{L}^{-1} \mathrm{Cr}(\mathrm{VI})$ for $120 \mathrm{~min}$, the XRD pattern of A-nZVI changes significantly (Fig. 1b). $\mathrm{Cr}$ (III) and iron phases are not detected, which indicates that A-nZVI has changed into amorphous rather than crystalline materials. Research of zero-valent iron and the reduction of chromium shows that the typical result from this deoxidation reaction is chromites,

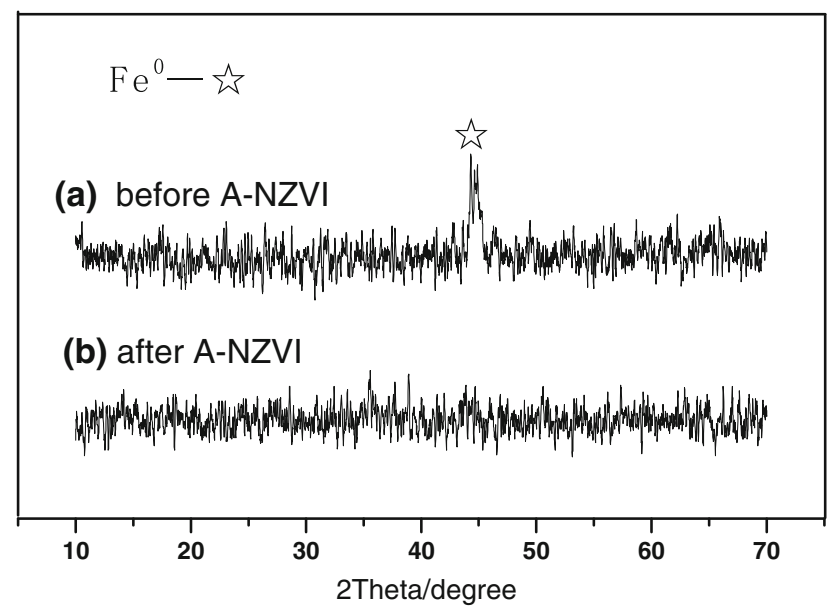

Fig. 1 Powder X-ray diffraction patterns of A-nZVI before and after reaction with $\mathrm{Cr}(\mathrm{VI})$ with some of the iron substituted for the chromium. Based on these results, the chromium end product is expected to have the same general chemical formula $\left(\mathrm{Cr}_{1-x} \mathrm{Fe}_{x}\right)(\mathrm{OH})_{3}$, where $x$ is typically about 0.33 . The results obtained by our study are in agreement with that of Ponder et al. (2000).

\section{SEM and EDX analysis}

Scanning electron microscopy (SEM) images of freshly synthesized nZVI and A-nZVI are shown in Fig. 2. It can be observed from Fig. 2a that nZVI particles with the diameter of 50-100 nm are in contact with each other. Although they are called "zero-valent iron nanoparticles," it should be noted that the stack of the aggregated spherical iron particles might be larger than a micrometer rather than existing in separated nanoparticles. This near-linear orientation is due to the magnetic properties of the iron species (Zhang et al. 2006). SEM image of A-nZVI is shown in Fig. 2b. Unlike nZVI, chain-like aggregates of iron nanoparticles can still be observed, as well as the separated iron nanospheres with the diameter of $60-120 \mathrm{~nm}$. These images show that the separation of spherical iron nanoparticles is possible in the presence of an organic dispersing agent (such as agar). Similar results were reported by using carboxymethyl cellulose as the stabilizer (Cirtiu et al. 2011). Figure 2c, d shows the synthesized A-nZVI after reaction. Chain-like iron nanospheres were replaced by flakes/aggregates. This may be attributed to the formation of co-precipitation involving $\mathrm{Cr}(\mathrm{VI})$, and the coating of oxide and hydroxide precipitates of $\mathrm{Cr}(\mathrm{III})$ and $\mathrm{Fe}(\mathrm{III})$ on the surface of the nanoparticles (Ponder et al. 2000). Figure 2e shows energy dispersive $\mathrm{X}$-ray (EDX) spectrum after A-nZVI de-oxidation reaction with $\mathrm{Cr}(\mathrm{VI})$ aqueous solution. It shows the $\mathrm{O}, \mathrm{Cr}, \mathrm{Fe}$ and $\mathrm{C}$ peak with the weight percent of $54.79 \%, 25.13 \%, 2.68 \%$ and $17.40 \%$ respectively, in the form of $\mathrm{Fe}_{2} \mathrm{O}_{3}$ and $\left(\mathrm{Cr}_{1-}\right.$ $\left.{ }_{x} \mathrm{Fe}_{x}\right)(\mathrm{OH})_{3}$ (Manning et al. 2007). In addition, the carbon would come from agar which can be used to modify nZVI.

\section{TEM analysis}

The distinct iron asthenospheres can be observed clearly in the TEM images of nZVI and A-nZVI as shown in Fig. 3. Figure $3 \mathrm{a}$ shows nZVI particles with the diameter of 50-100 nm in contact with each other from a chain-like structure. Spherical asthenospheres are covered by a thin agar layer as shown in Fig. 3b. The different contrast between the center and outer of the spheres indicates the core-shell structure. The nZVI particles are encapsulated into the microspheres by agar and are isolated from each other. For A-nZVI samples, a certain extent of dispersions of nanoparticles is clearly achieved. However, the dispersions are not uniform. The size distribution of nanospheres possesses a wide variation range from 60 to $120 \mathrm{~nm}$ 
Fig. 2 a SEM image of laboratory made nZVI, b ANZVI, c A-nZVI reacted with $\mathrm{Cr}(\mathrm{VI}), \mathbf{d} \mathrm{A}-\mathrm{nZVI}$ reacted with $\mathrm{Cr}(\mathrm{VI})-\times 20,000$ magnifications, e EDX element analysis of A-nZVI reacted with $\mathrm{Cr}(\mathrm{VI})$
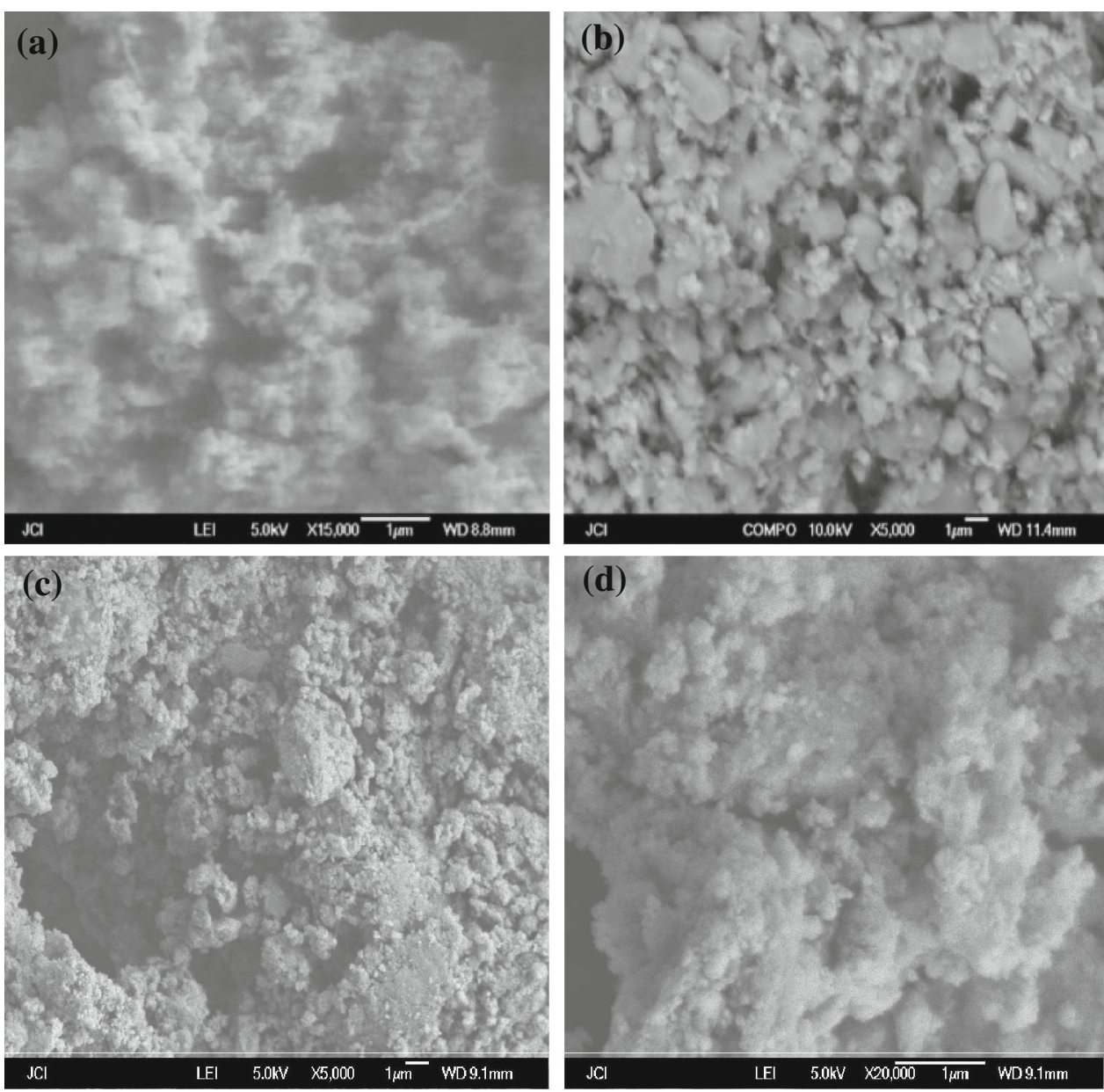

(e)

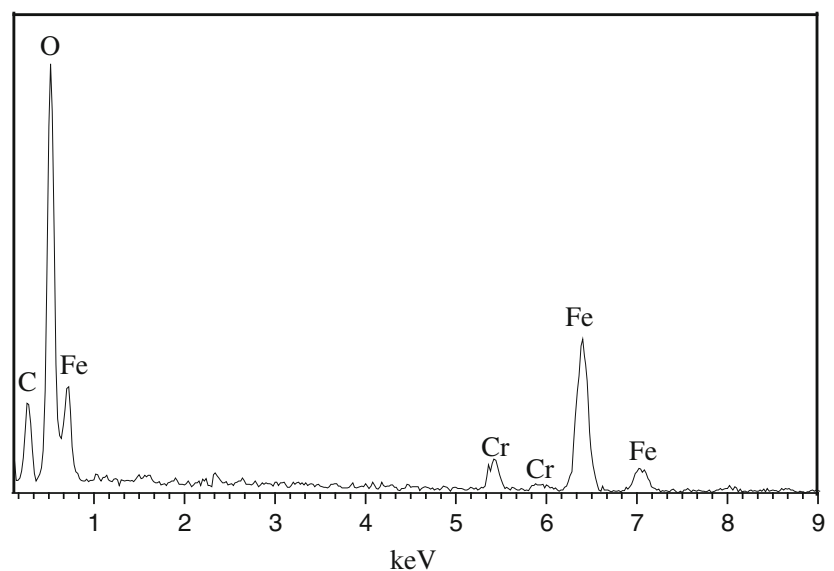

diameter. Figure $3 \mathrm{c}, \mathrm{d}$ shows that the surface passivation layers are formed after A-nZVI deoxidation reaction with $\mathrm{Cr}(\mathrm{VI})$, due to the precipitation of metal hydroxides on the surface of nZVI.

\section{FT-IR analysis}

Fourier-transform infrared (FT-IR) spectra of agar and AnZVI were scanned in the range of $400-4,000 \mathrm{~cm}^{-1}$ as shown in Fig. 4. The peak at 3,400, 2,900, 2,360, 1,650, 1,360, 1,160, 1,080, 930 and $893 \mathrm{~cm}^{-1}$ in agar (Fig. 4a) can be attributed to the stretching vibrations of $\mathrm{O}-\mathrm{H}$ groups. The overlapped bands centered at $2,900 \mathrm{~cm}^{-1}$ are due to the $-\mathrm{CH}_{2}$ asymmetric stretches. The peak at $1,650 \mathrm{~cm}^{-1}$, attributed to agar, is the characteristic absorption band of polysaccharides (Pourjavadi et al. 2009). An intense band between 800 and $1,200 \mathrm{~cm}^{-1}$, corresponding to $\mathrm{C}-\mathrm{O}$ stretching vibrations, exhibited 
Fig. 3 TEM image of laboratory made nZVI (a), A-NZVI (b); A-nZVI reacted with $\mathrm{Cr}(\mathrm{VI})(\mathbf{c})$; A-nZVI reacted with $\mathrm{Cr}(\mathrm{VI})$-magnifications (d)
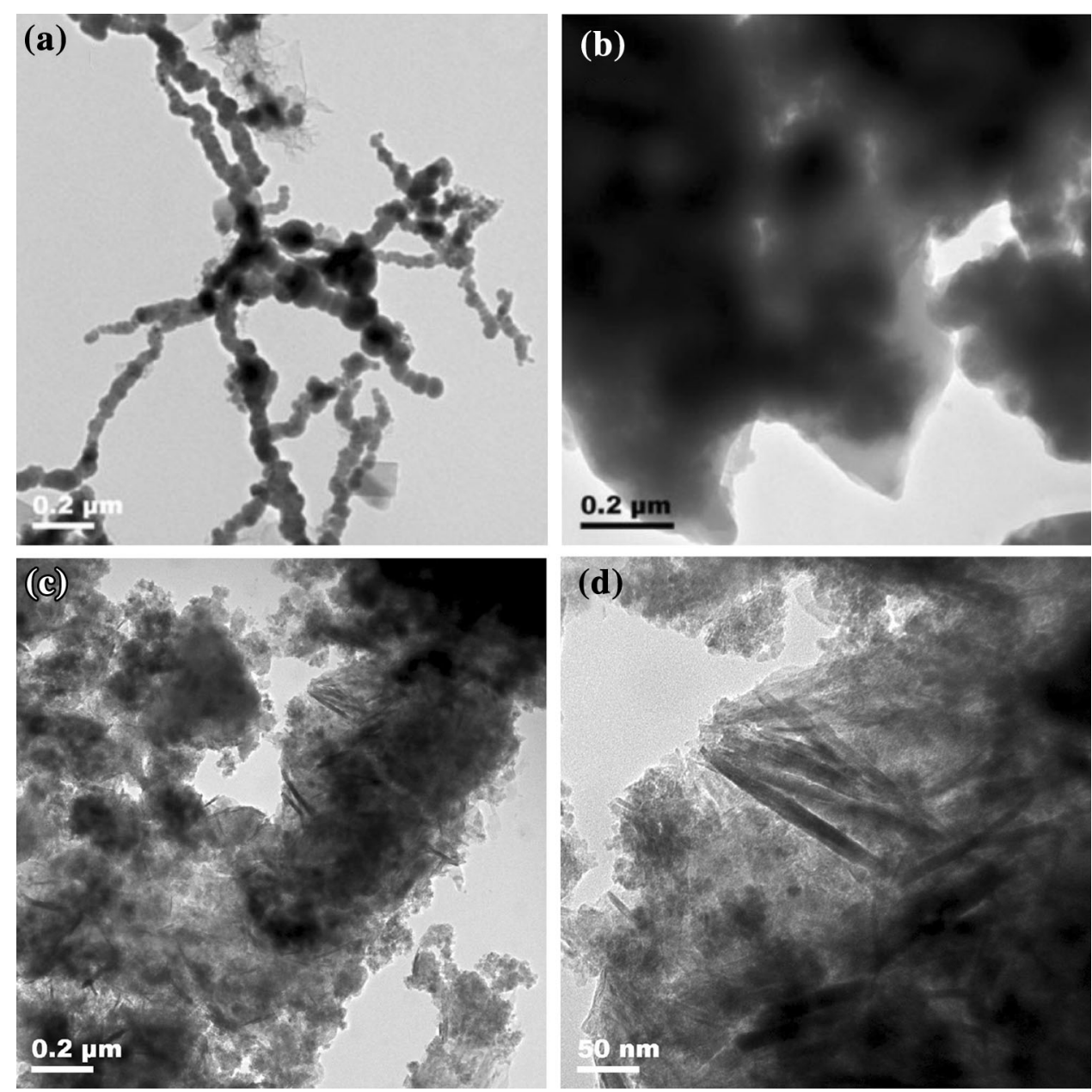

peaks centered at $1,160,930$ and $893 \mathrm{~cm}^{-1}$ ( $\left.\mathrm{v} \mathrm{C}-\mathrm{O}-\mathrm{C}\right)$ which are assigned to vibrational modes of the glycosidic linkage. The small peak at $930 \mathrm{~cm}^{-1}$ is due to the 3,6anhydro- $\alpha$-L-galactopyranose unit. Most of these bands disappeared in the composite, indicating loss of water molecules (Portilla 1976; Zhang et al. 2011). Strong bands at $<900 \mathrm{~cm}^{-1}$ in the nZVI alone (Fig. 4b), attributable in part to iron oxides on the surface (Zhang et al. 2011; Andrade et al. 2009), are weaker in the composite, indicating less oxidation of agar supported $\mathrm{Fe}^{0}$. The agar support may have reduced $\mathrm{Fe}$ (oxy) hydroxide formation, similar to the effect of montmorillon-ite-supported nZVI (Yuan et al. 2009). Bands at 1,360 and $1,100 \mathrm{~cm}^{-1}$ in the nZVI can be attributed to ethanol used in preparing the sample, but may also include bands associated with sulfate green rust $\left[\mathrm{Fe}_{4}^{\mathrm{II}} \mathrm{Fe}_{2}^{\mathrm{II}}(\mathrm{OH})_{12}\right]\left[\mathrm{SO}_{4} \cdot 3 \mathrm{H}_{2} \mathrm{O}\right]$ (Ponder et al. 2001; Gotic and Music 2007) and lepidocrocite ( $\gamma$-FeO$\mathrm{OH})\left(\right.$ Andrade et al. 2009) formation on some $\mathrm{Fe}^{0}$ surfaces.

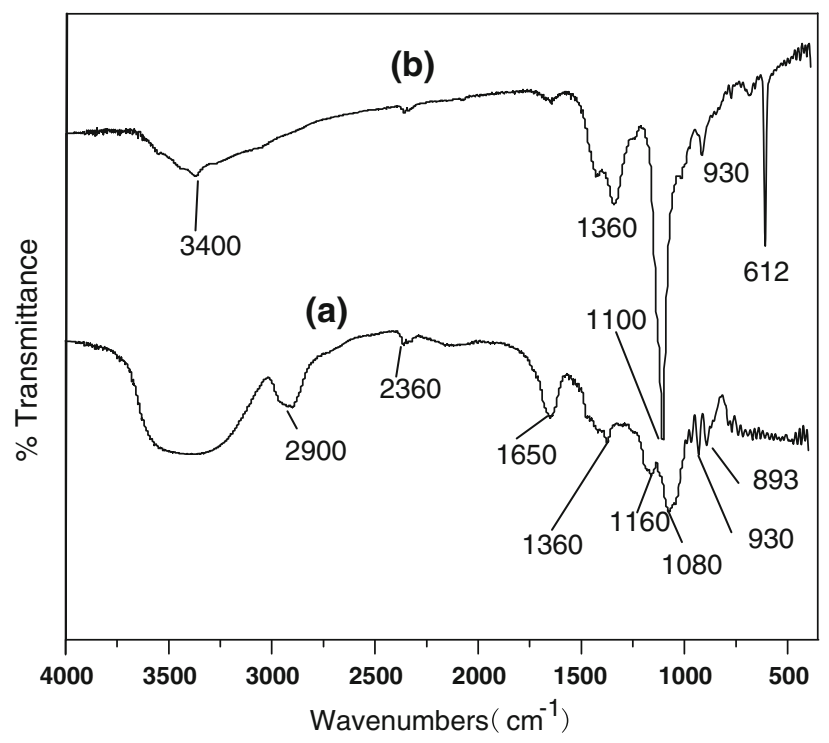

Fig. 4 FT-IR spectra of a agar and b A-nZVI 
The magnetism of A-nZVI

A-nZVI particles can be separated from liquid phase with additional magnetic field. A phenomenon was observed, namely that A-nZVI particle can be evenly dispersed in liquid for $24 \mathrm{~h}$, while bare iron particles are agglomerated and totally precipitate in aqueous solution in $5 \mathrm{~min}$. Therefore, we can see that A-nZVI particle via a rheological phase reaction method has better stability compared with bare iron particles in aqueous solution. In the permanent magnetic field, A-nZVI completely precipitates within $10 \mathrm{~min}$. A-nZVI can be rapidly dispersed in aqueous solution via shaking the conical flask without the magnetic field. The layer of agar on the surface of iron nanoparticles has minor impact on the magnetism of iron nanoparticles. Therefore, A-nZVI can be easily separated from aqueous solution with permanent magnet.

The removal of $\mathrm{Cr}(\mathrm{VI})$ experimental

\section{Influence of A-nZVI dosage and initial concentrations of $\mathrm{Cr}(\mathrm{VI})$}

The influence of A-nZVI dosage on $\mathrm{Cr}(\mathrm{VI})$ reduction was examined using the dosages between 0.25 and $1 \mathrm{~g} \mathrm{~L}^{-1}$. The residual $\mathrm{Cr}(\mathrm{VI})$ is apparently a function of the applied A-nZVI dose (Fig. 5a): the higher of the A-nZVI concentration, the lower of the residual chromium in solution. A-nZVI concentration of $0.75 \mathrm{~g} \mathrm{~L}^{-1}$ can completely reduce $\mathrm{Cr}(\mathrm{VI})$ to $\mathrm{Cr}(\mathrm{III})$. The increases of nanoparticle concentrations generally increase the number of binding sites, which in turn increase the reduction of $\mathrm{Cr}(\mathrm{VI})$. The uptake is a measurement of the amount of $\mathrm{Cr}(\mathrm{VI})$ ions bound by unit weight of material. The magnitude decreased with the increasing of the A-nZVI dose.

The effect of initial concentrations ranging from 10 to $100 \mathrm{mg} \mathrm{L}^{-1}, \mathrm{pH}=5$ and $0.75 \mathrm{~g} \mathrm{~L}^{-1} \mathrm{~A}-\mathrm{nZVI}$ at room temperature on the removal of $\mathrm{Cr}(\mathrm{VI})$ was discussed. As shown in Fig. 5b, the removal of $\mathrm{Cr}(\mathrm{VI})$ decrease with the increase in initial concentration of $\mathrm{Cr}(\mathrm{VI})$. Complete removal of $\mathrm{Cr}(\mathrm{VI})$ is achieved with the concentrations of $\mathrm{Cr}(\mathrm{VI})$ ranging from 10 to $50 \mathrm{mg} \mathrm{L}^{-1}$, and $58.05 \%$ of $\mathrm{Cr}(\mathrm{VI})$ is removed with the $\mathrm{Cr}(\mathrm{VI})$ concentration of $100 \mathrm{mg} \mathrm{L}^{-1}$ after $5 \mathrm{~h}$ of de-oxidation reaction. This might be due to the fact that, for a fixed amount of A-nZVI, the available sites for adsorption remain constant, as the initial concentration of $\mathrm{Cr}(\mathrm{VI})$ increasing, the limit activity hinders the de-oxidation reaction leading to low removal of $\mathrm{Cr}(\mathrm{VI})$ efficiency.

\section{Effect of $p H$}

To investigate the effect of $\mathrm{pH}$ value on the removal of $\mathrm{Cr}(\mathrm{VI})$, batch experiments were carried out with the $\mathrm{pH}$ values ranging from 3.0 to 11.0 with initial $\mathrm{Cr}(\mathrm{VI})$ $\left(20 \mathrm{mg} \mathrm{L}^{-1}\right) / \mathrm{A}$-nZVI ratios of 0.1 at $25^{\circ} \mathrm{C}$. As shown in Fig. 6a, the removal of $\mathrm{Cr}(\mathrm{VI})$ decreases with the increase in the initial $\mathrm{pH}$ values from 3.0 to 11.0 , and nearly $100 \%$ of $\mathrm{Cr}(\mathrm{VI})$ is removed within $60 \mathrm{~min}$ at $\mathrm{pH}=3$. The removal efficiency of $\mathrm{Cr}(\mathrm{VI})$ increases with the decrease in $\mathrm{pH}$ values, which is because $\mathrm{CrO}_{4}{ }^{2-}, \mathrm{HCrO}_{4}{ }^{-}, \mathrm{H}_{2} \mathrm{CrO}_{4}$, $\mathrm{HCr}_{2} \mathrm{O}_{7}{ }^{-}$or $\mathrm{Cr}_{2} \mathrm{O}_{7}{ }^{2-}$ existed on the $\mathrm{pH}$ of the medium in the total concentration (Park et al. 2007). In the solutions of low $\mathrm{pH}$ values, $\mathrm{HCrO}_{4}{ }^{-}$is the prevalent form of hexavalent chromium, which subsequently shifts to $\mathrm{CrO}_{4}{ }^{2-}$ and $\mathrm{Cr}_{2} \mathrm{O}_{7}{ }^{2-}$ as the $\mathrm{pH}$ value increases. Low acidic conditions can also cause a high extent of protonated of the nanoparticles surface, resulting in a strong attraction between the negatively charged complex ions and the positively charged surface (Zhang et al. 2011).

Zero-valent iron $\left(\mathrm{Fe}^{0}\right)$ is a moderate reducing reagent, which can react with dissolved oxygen and to some extent with water (Prabhakaran et al. 2009):
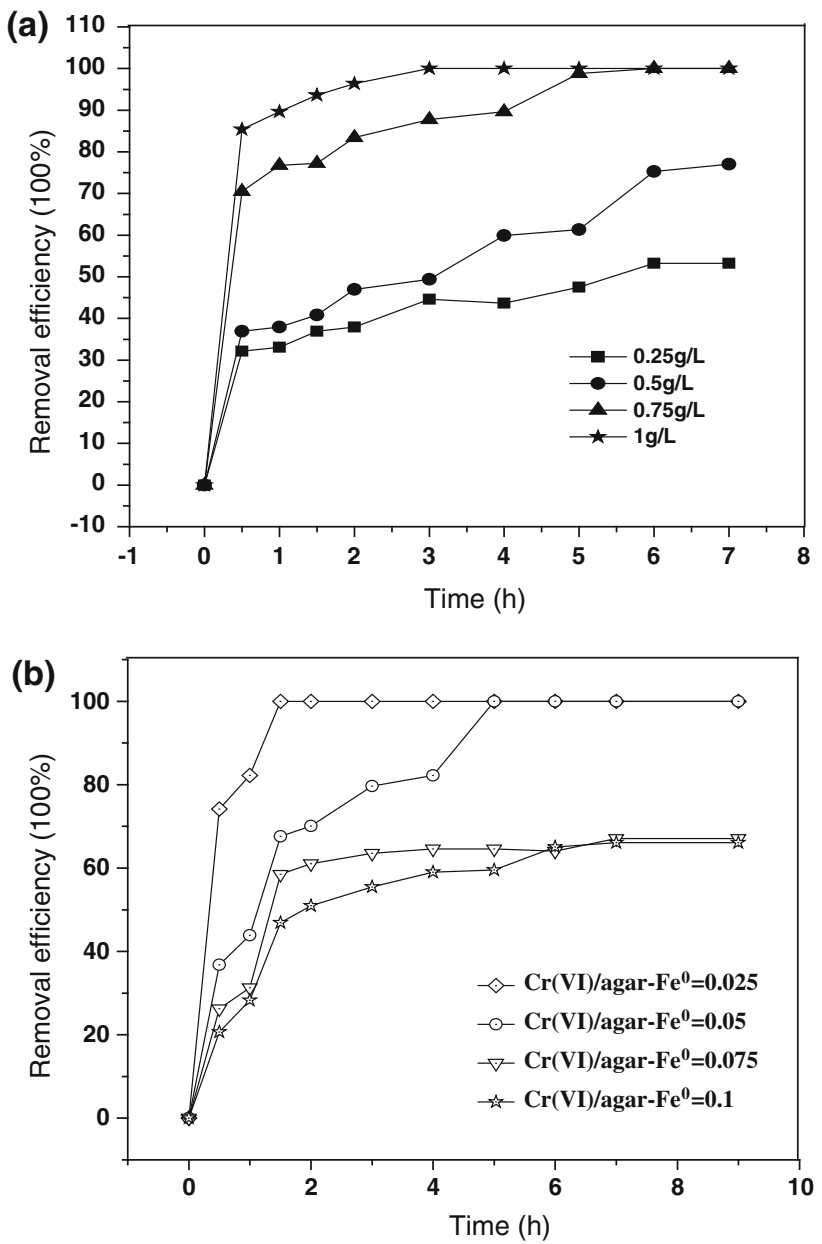

Fig. 5 Removal of $\mathrm{Cr}(\mathrm{VI})$ in the aqueous phase at a various A-nZVI dosage and $\mathbf{b}$ initial concentration as a function of time 

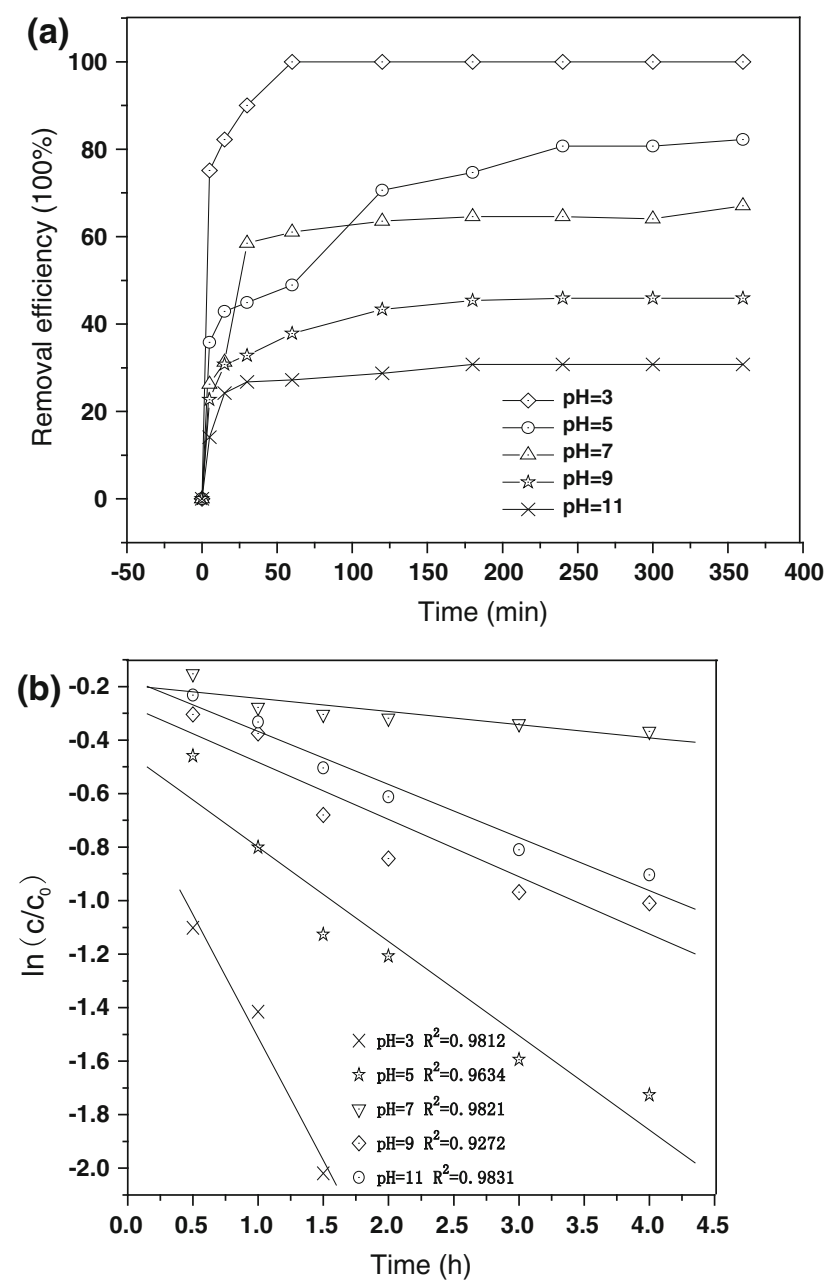

Fig. 6 aRemoval of $\mathrm{Cr}$ (VI) as a function of time at different $\mathrm{pH}$ values. b Dynamics curve for treatment of Cr(VI) with A-nZVI on different initial $\mathrm{pH}$

$2 \mathrm{Fe}^{0}+4 \mathrm{H}^{+}+\mathrm{O}_{2} \rightarrow 2 \mathrm{Fe}^{2+}+2 \mathrm{H}_{2} \mathrm{O}$

$\mathrm{Fe}^{0}+2 \mathrm{H}_{2} \mathrm{O} \rightarrow \mathrm{Fe}^{2+}+\mathrm{H}_{2}+2 \mathrm{OH}^{-}$

Reduction of $\mathrm{Cr}(\mathrm{VI})$ in acidic conditions is described as follows:

$\mathrm{Fe}^{2+}+\mathrm{H}_{2} \mathrm{CrO}_{4}+\mathrm{H}^{+} \rightarrow \mathrm{Fe}^{3+}+\mathrm{H}_{3} \mathrm{CrO}_{4}$

$\mathrm{Fe}^{2+}+\mathrm{H}_{3} \mathrm{CrO}_{4}+\mathrm{H}^{+} \rightarrow \mathrm{Fe}^{3+}+\mathrm{H}_{4} \mathrm{CrO}_{4}$

$\mathrm{Fe}^{2+}+\mathrm{H}_{4} \mathrm{CrO}_{4}+\mathrm{H}^{+} \rightarrow \mathrm{Fe}^{3+}+\mathrm{Cr}(\mathrm{OH})_{3}+\mathrm{H}_{2} \mathrm{O}$

To simplify the process, the reaction of $\mathrm{Cr}(\mathrm{VI})$ reduced by iron nanoparticles is presented as:

$2 \mathrm{CrO}_{4}^{2-}+3 \mathrm{Fe}^{0}+10 \mathrm{H}^{+} \rightarrow 2 \mathrm{Cr}(\mathrm{OH})_{3}+3 \mathrm{Fe}^{2+}+2 \mathrm{H}_{2} \mathrm{O}$

The iron oxidation and reduction reactions are favored at low $\mathrm{pH}$. Moreover, the effect of $\mathrm{pH}$ value on the reduction might be influenced not only by $\mathrm{H}^{+}$consumption on the overall reaction and iron geochemistry but also the relatively low solubility of $\mathrm{Cr}(\mathrm{III})$ oxides and mixed Cr(III)/iron (III) oxides (Sass and Rai 1987). When the $\mathrm{pH}$ value is higher than 8 , only $\mathrm{CrO}_{4}{ }^{2-}$ is stable (Weckhuysen et al. 1996).

The influence of initial $\mathrm{pH}$ value on the removal rates of $\mathrm{Cr}(\mathrm{VI})$ was investigated, and the results are shown in Fig. 6b. For various values of $\mathrm{pH}$ from 3.0 to 11.0 with an initial $\mathrm{Cr}(\mathrm{VI}) / \mathrm{A}-\mathrm{nZVI}$ ratio of 0.1 at $25^{\circ} \mathrm{C}$, the $k_{\text {obs }}$ values of the rate constant are 0.9178, 0.2136, 0.1984 and $0.0049 \mathrm{~min}^{-1}$, respectively. Obviously, plots of $\ln \left(c / c_{0}\right)$ versus time are linear with a high correlation coefficient $\left(R^{2}>0.9\right)$ under various conditions (Fig. 6b). This is similar to the results reported in the literature (Shi et al. 2011).

\section{Effect of initial $C r(V I) / A-n Z V I$ ratios}

Figure 7a shows the effect of initial Cr(VI)/A-nZVI ratios from 0.025 and 0.1 on the removal of $\mathrm{Cr}(\mathrm{VI})$ at $\mathrm{pH}$ value of 7. The residual concentration of $\mathrm{Cr}(\mathrm{VI})$ is a function of the initial $\mathrm{Cr}(\mathrm{VI}) / \mathrm{A}-\mathrm{nZVI}$ ratios: the lower of $\mathrm{Cr}(\mathrm{VI}) / \mathrm{A}-\mathrm{nZVI}$ ratios, the lower of the residual chromium in solution. As shown in Fig. 7a, the reduction of $\mathrm{Cr}(\mathrm{VI})$ increases quickly at the first $2 \mathrm{~h}$, and then, the reduction maintained at a even rate with the increase in reaction time. An initial $\mathrm{Cr}(\mathrm{VI}) / \mathrm{A}$ nZVI ratio of 0.025 could completely reduce $\mathrm{Cr}(\mathrm{VI})$. The increase in the concentration of A-nZVI generally increases the number of binding sites, which in turn increases the reduction amount of $\mathrm{Cr}(\mathrm{VI})$.

The reaction of A-nZVI with $\mathrm{Cr}(\mathrm{VI})$ belongs to a heterogeneous reaction in aqueous solution. Therefore, the reaction process can be described as Langmuir-Hinshelwood dynamics model (Ho and McKay 1999). These results reveal that the reduction follows a pseudo-first-order kinetic model which can be represented by the following equation:

$v=-\frac{\mathrm{d} c}{\mathrm{~d} t}=K_{\mathrm{SA}} a_{s} \rho_{m} c$

where $c$ is the concentration $\left(\mathrm{mg} \mathrm{L}^{-1}\right)$ of contaminant in solution, $k_{\mathrm{SA}}$ is the specific reaction rate constant bounded to the SSA of the materials $\left(\mathrm{L} \mathrm{h}^{-1} \mathrm{~m}^{-2}\right), a_{\mathrm{s}}$ is the specific surface area $\left(\mathrm{m}^{2} \mathrm{~g}^{-1}\right)$, and $\rho_{\mathrm{m}}$ is the mass concentration $\left(\mathrm{g} \mathrm{L}^{-1}\right)$. Since $k_{\mathrm{SA}}, a_{\mathrm{s}}$ and $\rho_{\mathrm{m}}$ are constant for a given reaction, the product of the three parameters can be replaced by one parameter $k_{\mathrm{obs}}$. Then, an evaluation of integrals Eq. (8) can be written as:

$\ln \frac{c}{c_{0}}=-K_{\mathrm{obs}} t$

where $k_{\mathrm{obs}}$ is the observed rate constant of a pseudo-firstorder reaction $\left(\mathrm{min}^{-1}\right)$ can be determined by the slope of plotting $\ln \left(c / c_{0}\right)$ versus time. 

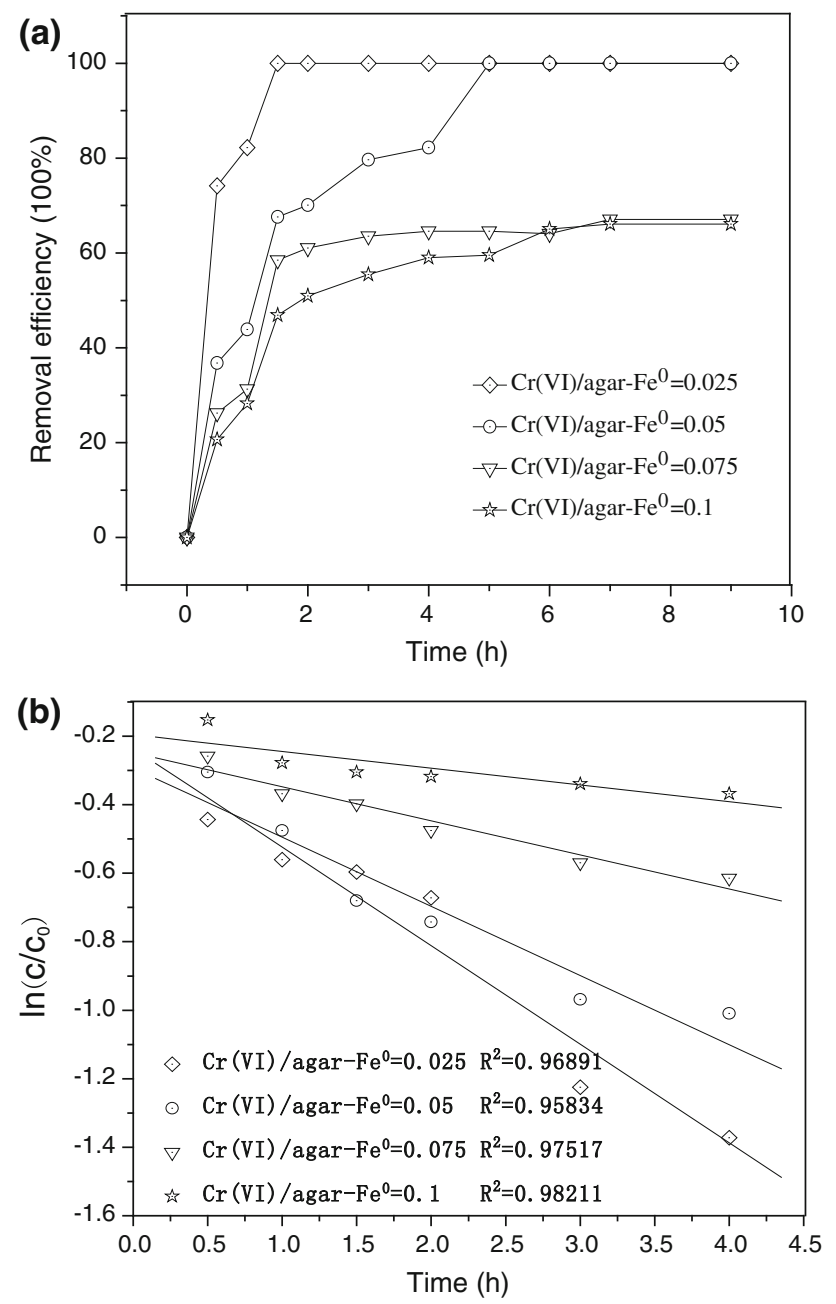

Fig. 7 a Removal of $\mathrm{Cr}$ (VI) as a function of time with different initial Cr (VI)/A-nZVI ratios. b Dynamics curve for treatment of $\mathrm{Cr}(\mathrm{VI})$ with $\mathrm{Agar}-\mathrm{Fe}^{0}$ on different initial $\mathrm{Cr}(\mathrm{VI}) / \mathrm{A}-\mathrm{nZVI}$ ratio

Figure $7 \mathrm{~b}$ shows the plot of the removal of $\mathrm{Cr}(\mathrm{VI})$ by A-nZVI particles using the pseudo-first-order kinetics. The modified first-order model agrees with the kinetics in the whole de-oxidation reaction process. The influence of initial $\mathrm{Cr}(\mathrm{VI}) / \mathrm{A}-\mathrm{nZVI}$ ratios on the removal rates of $\mathrm{Cr}(\mathrm{VI})$ was investigated. For $100 \mathrm{~mL} \mathrm{Cr}(\mathrm{VI})$ solution with the initial concentration of $20 \mathrm{mg} \mathrm{L}^{-1}$ and $0.025-0.1$ initial ratios of $\mathrm{Cr}(\mathrm{VI}) / \mathrm{A}-\mathrm{nZVI}$, the $k_{\mathrm{obs}}$ values of the rate constants are $0.2931,0.2483,0.2360$ and $0.1950 \mathrm{~min}^{-1}$, respectively. The values of observed rate constant $\left(k_{\mathrm{obs}}\right)$ are obtained with the regression coefficient $\left(R^{2}\right)$ around 0.9 (Fig. 7b). Analysis of the data reveals that the rate constants decrease from 0.2931 to $0.1950 \mathrm{~min}^{-1}$ as the initial ratios of $\mathrm{Cr}(\mathrm{VI}) / \mathrm{A}$-nZVI increase from 0.025 to 0.1 . This can be ascribed to the fact that the specific surface area is constant for a certain material, and the portion of the active sites on the surface of A-nZVI is constant when the portion of iron is fixed. These phenomena could be attributed to an increasing of the available active sites resulting from the increasing of the A-nZVI dosage. The results obtained are in agreement with previous studies conducted on reaction kinetics (Zhang et al. 2009).

\section{Comparison of $n Z V I$ and $A-n Z V I$ on the removal of $C r(V I)$}

The initial $\mathrm{pH}=5, \mathrm{Cr}(\mathrm{VI})$ concentration was $20 \mathrm{mg} \mathrm{L}^{-1}$, and nZVI concentration was $0.75 \mathrm{~g} \mathrm{~L}^{-1}$. It can be seen that, under identical conditions, the removal of $\mathrm{Cr}(\mathrm{VI})$ by nZVI and A-nZVI de-oxidation reaction for $5 \mathrm{~h}$ were 82.27 and $100.00 \%$, respectively. This result is supported by the literature (Zhang et al. 2010). The relatively lower removal of $\mathrm{Cr}(\mathrm{VI})$ by nZVI was caused by the aggregation of nZVI leading to the decrease in its specific surface area and reaction activity. A-nZVI is a stable material and easy to be dispersed in aqueous solution, and with the presence of agar dissolved, the reaction activity of nZVI increased. In addition, the removal of $\mathrm{Cr}(\mathrm{VI})$ by agar is only $3.9 \%$ due to adsorption effect. More importantly, the removal of $\mathrm{Cr}(\mathrm{VI})$ by A-nZVI is nearly $100 \%$ after de-oxidation reaction for $5 \mathrm{~h}$, which is much higher than that by nZVI, and even distinctly superior to the simple combination of reduction effect by nZVI and adsorption by agar. For A-nZVI and nZVI, a significant concentration drop in the first $0.5 \mathrm{~h}$ is observed. For the control experiment, agar is used for a very small amount of $\mathrm{Cr}(\mathrm{VI})$ concentration drop in the first $0.5 \mathrm{~h}$ which will help us understand the reduction mechanism. According to the mechanism of the reduction of $\mathrm{Cr}(\mathrm{VI})$ (Hoch et al. 2008), the cooperation of agar and nZVI in the agar-nZVI system is favorable for the removal of $\mathrm{Cr}(\mathrm{VI})$, and hence, the removal rates of $\mathrm{Cr}(\mathrm{VI})$ by agar-nZVI do not decrease comparing to nZVI. The reactivity of entrapped nZVI in calcium alginate beads is comparable to bare nZVI. The results also demonstrate that when the removal of $\mathrm{Cr}(\mathrm{VI})$ from solution reached equilibrium in the first $3 \mathrm{~h}$ using nZVI, it took $5 \mathrm{~h}$ using A-nZVI (Bezbaruah et al. 2009). This indicated that the removal rate of $\mathrm{Cr}(\mathrm{VI})$ by $\mathrm{nZVI}$ is much faster than that by A-nZVI.

\section{The reaction mechanism removing of $C r(V I)$ by $A-n Z V I$}

After the reaction process of $\mathrm{Cr}(\mathrm{VI})$ degradation by A-nZVI, A-nZVI evenly dispersed in aqueous solution, the agar layer of iron surface completely dissolved in aqueous solution leads to the $\mathrm{Fe}^{0}$ exposure to water. The pathway for $\mathrm{Cr}(\mathrm{VI})$ removal in aqueous solution is summarized as follows. Removal of $\mathrm{Cr}(\mathrm{VI})$ by $\mathrm{Fe}^{0}$ follows the pathway of sorption and reductive precipitation/immobilization (Lai and Lo 2008; Liu et al. 2008). Initially, $\mathrm{Cr}(\mathrm{III})$ adsorbed on the surface of $\mathrm{Fe}^{0}$ where electron transfer takes place. After sorption, $\mathrm{Cr}(\mathrm{IIII})$ content is reduced with the oxidation of $\mathrm{Fe}^{0}$ to $\mathrm{Fe}^{2+}$ and $\mathrm{Fe}^{3+}$. 
Spectroscopic data showed that the $\mathrm{Cr}$ (III) precipitation can form $\mathrm{Cr}$ or $\mathrm{Cr}-\mathrm{Fe}$ mixture such as oxides/hydroxides/oxyhydroxides (Powell et al. 1995; Pratt et al. 1997). These precipitations were mostly irregular strips, chick-footmark-like or boulder-like forms (Lai and Lo 2008). $\mathrm{Cr}^{3+}$ and $\mathrm{Fe}^{3+}[\mathrm{r}$ $\left(\mathrm{Cr}^{3+}\right)=0.615 \AA, \mathrm{r}\left(\mathrm{Fe}^{3+}\right)=0.645 \AA$ ] have the similar ionic radii and the valence states; $\mathrm{Cr}^{3+}$ substitutes $\mathrm{Fe}^{3+}$ and incorporates into iron oxy-hydroxide shell, forming $\mathrm{Cr}-\mathrm{Fe}$ mixture such as oxides/hydroxides/oxy-hydroxides with a general chemical formula $\mathrm{Cr}_{\mathrm{x}} \mathrm{Fe}_{1-\mathrm{x}}(\mathrm{OH})_{3}$.

\section{Conclusion}

In this study, A-nZVI was synthesized using agar as the stabilizer via a rheological phase reaction method. Batch experiments indicated that A-nZVI had superior removal capability of $\mathrm{Cr}(\mathrm{VI})$ in various conditions. The $\mathrm{pH}$ value can significantly affect the removal efficiency of $\mathrm{Cr}(\mathrm{VI})$. The high removal efficiency of $\mathrm{Cr}(\mathrm{VI})(100 \%)$ was obtained under the condition of $50 \mathrm{mg} \mathrm{L}^{-1}$ of $\mathrm{Cr}(\mathrm{VI})$ at the optimal $\mathrm{pH}$ value of 3 and $\mathrm{Cr}(\mathrm{VI}) / \mathrm{A}-\mathrm{nZVI}$ molar ratio of 0.025 for $2 \mathrm{~h}$ at room temperature. The removal rate of $\mathrm{Cr}(\mathrm{VI})$ was fitted to the modified pseudo-first-order kinetic equation with respect to $\mathrm{Cr}(\mathrm{VI})$ concentration.

Acknowledgments This work has been funded by the National Natural Science Foundation of China (No. 51268018), supported by the Open Funds from Key Laboratory of Jiangsu Province for Chemical Pollution Control and Resources Reuse (Nanjing University of Science and Technology), Fundamental Research Funds for the Central Universities (No. 30920130122007), and Jingdezhen Science and Technology Bureau (No.701301257). The authors are grateful to National Engineering Research Center for Domestic and Building Ceramics, JCU for the assistance in analytical measurements.

\section{References}

Alidokht L, Khataee AR, Reyhanitabar A, Oustan S (2011) Reductive removal of $\mathrm{Cr}(\mathrm{VI})$ by starch-stabilized $\mathrm{Fe}^{0}$ nanoparticles in aqueous solution. Desalination 270:105-110

Andrade AL, Souza DM, Pereira MC, Fabris JD, Domingues RZ (2009) Synthesis and characterization of magnetic nanoparticles coated with silica through a sol-gel approach. Cerâmica $55: 420-424$

Bezbaruah AN, Krajangpan S, Chisholm BJ, Khan E, Bermudez JJ (2009) Entrapment of iron nanoparticles in calcium alginate beads for groundwater remediation applications. J Hazard Mater 166:1339-1343

Choi H, Agarwal S, Al-Abed SR (2009) Adsorption and simultaneous dechlorination of $\mathrm{PCBs}$ on $\mathrm{GAC} / \mathrm{Fe} / \mathrm{Pd}$ : mechanistic aspects and reactive capping barrier concept. Environ Sci Technol 43:488-493

Cirtiu CM, Raychoudhury T, Ghoshal S (2011) Systematic comparison of the size, surface characteristics and colloidal stability of zero valent iron nanoparticles pre- and post-grafted with common polymers. Colloid Surface A 39:95-104
Crane RA, Scott TB (2012) Nanoscale zero-valent iron: future prospects for emerging water treatment technology. J Hazard Mater 211-212:122-125

Elliott DW, Lien HL, Zhang WX (2009) Degradation of lindane by zero-valent iron nanoparticles. J Environ Energy 135:317-324

Flury B, Eggenberger U, Mader U (2009) First results of operating and monitoring an innovative design of a permeable reactive barrier for the remediation of chromate contaminated groundwater. Appl Geochem 24:687-696

Franco DV, Silva LMD, Jardim WF (2009) Reduction of hexavalent chromium in soil and ground water using zero-valent iron under batch and semi-batch conditions. Water Air Soil Pollut 197:49-60

Gheju M (2011) Hexavalent chromium reduction with zero-valent iron (ZVI) in aquatic systems. Water Air Soil Pollut 222(1): $103-148$

Gotic M, Music S (2007) Mössbauer, FT-IR and FE SEM investigation of iron oxides precipitated from $\mathrm{FeSO}_{4}$ solutions. J Mol Struct 834-836:445-453

He F, Zhao D (2005) Preparation and characterization of a new class of starch-stabilized bimetallic nanoparticles for degradation of chlorinated hydrocarbons in water. Environ Sci Technol 39:3314-3320

He F, Zhao D, Liu J, Roberts CB (2007) Stabilization of Fe/pd bimetallic nanoparticles with sodium carboxymethyl cellulose to facilitate dechlorination of trichloroethene and soil transportability. Ind Eng Chem Res 46:29-34

Ho YS, McKay G (1999) Pseudo-second order model for sorption processes. Process Biochem 34:451-465

Hoch LB, Mack EJ, Hydutsky BW, Hershman JM, Skluzacek JM, Mallouk TE (2008) Carbothermal synthesis of carbon-supported nanoscale zero-valent iron particles for the remediation of hexavalent chromium. Environ Sci Technol 42:2600-2605

Huang QG, Shi XY, Pinto RA, Petersen EJ, Weber WJ (2008) Tunable synthesis and immobilization of zero-valent iron nanoparticles for environmental applications. Environ Sci Technol 42:8884-8889

Jiang J, Li L, Xu F, Xie Y (2007) Preparation and magnetic properties of $\mathrm{Zn}-\mathrm{Cu}-\mathrm{Cr}-\mathrm{Sm}$ ferrite via a rheological phase reaction method. Mater Sci Eng B Adv 137:166-169

Lai KCK, Lo IMC (2008) Removal of chromium(VI) by acid washed zero-valent iron under various groundwater geochemistry conditions. Environ Sci Technol 42:1238-1244

Legrand L, Figuigui EA, Mercier F, Chausse A (2004) Reduction of aqueous chromate by $\mathrm{Fe}(\mathrm{II}) / \mathrm{Fe}(\mathrm{III})$ carbonate green rust: kinetic and mechanistic studies. Environ Sci Technol 38:4587-4595

Liu T, Tsang DCW, Lo IMC (2008) Chromium (VI) reduction kinetics by zero-valent iron in moderately hard water with humic acid: iron dissolution and humic acid adsorption. Environ Sci Technol 42:2092-2098

Manning BA, Kiser JR, Kwon H, Kanels SR (2007) Spectroscopic investigation of $\mathrm{Cr}(\mathrm{III})$-and $\mathrm{Cr}(\mathrm{VI})$-treated nanoscale zerovalent iron. Environ Sci Technol 41:586-592

Norziah MH, Foo SL, Karim AA (2006) Rheological studies on mixtures of agar (Gracilaria changii) and $\kappa$-carrageenan. Food Hydrocolloid 20:204-217

O'Carroll D, Sleep B, Krol M, Boparai H, Kocur C (2013) Nanoscale zero valent iron and bimetallic particles for contaminated site remediation. Adv Water Resour 51:104-122

Owlad M, Kheireddine MA, Daud WAW, Baroutian S (2009) Removal of hexavalent chromium contaminated water and wastewater: a review. Water Air Soil Pollut 200:59-77

Park D, Yun YS, Ahn CK, Park JM (2007) Kinetics of the reduction of hexavalent chromium with the brown seaweed ecklonia biomass. Chemosphere 66:939-946 
Ponder SM, Darab JG, Mallouk TE (2000) Remediation of Cr(VI) and $\mathrm{Pb}$ (II) aqueous solutions using supported, nano-scale zero-valent iron. Environ Sci Technol 34:2564-2569

Ponder SM, Darab JG, Bucher J, Caulder D, Craig I, Davis L, Edelstein N, Lukens W, Nitsche H, Rao L, Shuh DK, Mallouk TE (2001) Surface chemistry and electrochemistry of supported zerovalent iron nanoparticles in the remediation of aqueous metal contaminants. Chem Mater 13:479-486

Portilla VI (1976) The nature of hydrogen bonds and water in legrandite by IR spectroscopy. Am Mineral 61:95-99

Pourjavadi A, Farhadpour B, Seidi F (2009) Synthesis and investigation of swelling behavior of new agar based superabsorbent hydrogel as a candidate for agrochemical delivery. J Polym Res 16:655-665

Powell RM, Puls RW, Hightower SK, Sabatini DA (1995) Coupled iron corrosion and chromate reduction: mechanism of subsurface remediation. Environ Sci Technol 29(8):1913-1922

Prabhakaran SK, Vijayaraghavan K, Balasubramanian R (2009) Removal of ions by spent tea and coffee dusts: reduction to $\mathrm{Cr}$ (III) and biosorption. Ind Eng Chem Res 48:2113-2117

Pratt AR, Blowes DW, Ptacek CJ (1997) Products of chromate reduction on proposed subsurface remediation material. Environ Sci Technol 31:2492-2498

Sass BM, Rai D (1987) Solubility of amorphous chromium (III)-iron (III) hydroxide solid solutions. Inorg Chem 26:2228-2232

Schrick B, Hydutsky BW, Blough JL, Mallouk TE (2004) Delivery vehicles for zerovalent metal nanoparticles in soil and groundwater. Chem Mater 16:2187-2193

Shi LN, Lin YM, Zhang X (2011) Synthesis, characterization and kinetics of bentonite supported nZVI for the removal of $\mathrm{Cr}(\mathrm{VI})$ from aqueous solution. Chem Eng J 171:612-617
Shukla MK, Singh RP, Reddy CRK (2012) Synthesis and characterization of agar-based silver nanoparticles and nanocomposite film with antibacterial applications. Bioresour Technol 107:295-300

Singh R, Misra V, Singh RP (2011) Synthesis, characterization and role of zero-valent iron nanoparticle in removal of hexavalent chromium from chromium-spiked soil. J Nanpart Res 13:4063-4073

Weckhuysen BM, Wachs IE, Schoonheydt RA (1996) Surface chemistry and spectroscopy of chromium in inorganic oxides. Chem Rev 96:3327-3349

Yuan P, Fan M, Yang D, He H, Liu D, Yuan A, Zhu J, Chen T (2009) Montmorillonite-supported magnetite nanoparticles for the removal of hexavalent chromium $[\mathrm{Cr}(\mathrm{VI})]$ from aqueous solutions. J Hazard Mater 166:821-829

Zhang H, Jin Z, Han L, Qin C (2006) Synthesis of nanoscale zerovalent iron supported on exfoliated graphite for removal of nitrate. Trans Nonferr Metals Soc China 16:345-349

Zhang X, Lin Y, Chen Z (2009) 2,4,6-Trinitrotoluene reduction kinetics in aqueous solution using nanoscale zero-valent iron. J Hazard Mater 165:923-927

Zhang X, Lin S, Lu XQ, Chen ZL (2010) Removal of Pb(II) from water using natural kaolin loaded with synthesized nanoscale zero-valent iron. Chem Eng J 163:243-248

Zhang X, Lin S, Chen Z, Megharaj M, Naidu R (2011) Kaolinitesupported nanoscale zero-valent iron for removal of $\mathrm{Pb} 2+$ from aqueous solution: reactivity, characterization and mechanism. Water Res 45:3481-3488

Zhu BW, Lim TT, Feng J (2006) Reductive dechlorination of 1,2,4trichlorobenzene with palladized nanoscale $\mathrm{Fe}^{0}$ particles supported on chitosan and silica. Chemosphere 65:1137-1145 